\title{
Reproducibility of Electromyography Signal Amplitude during Repetitive Dynamic Contraction
}

\author{
Seung-Min Mo, Jong-Seon Kwag, Myung-Chul Jung \\ Department of Industrial and Information Systems Engineering, Ajou University, Suwon, 443-749
}

\begin{abstract}
Objective: The aim of this study is to evaluate the fluctuation of signal amplitude during repetitive dynamic contraction based on surface electromyography(EMG). Background: The most previous studies were considered isometric muscle contraction and they were difference to smoothing window length by moving average filter. In practical, the human movement is dynamic state. Dynamic EMG signal which indicated as the nonstationary pattern should be analyzed differently compared with the static EMG signal. Method: Ten male subjects participated in this experiment, and EMG signal was recorded by biceps brachii, anterior/posterior deltoid, and upper/lower trapezius muscles. The subject was performed to repetitive right horizontal lifting task during ten cycles. This study was considered three independent variables(muscle, amplitude processing technique, and smoothing window length) as the within-subject experimental design. This study was estimated muscular activation by means of the linear envelope technique(LE). The dependent variable was set coefficient of variation(CV) of LE for each cycle. Results: The ANOVA results showed that the main and interaction effects between the amplitude processing technique and smoothing window length were significant difference. The CV value of peak LE was higher than mean LE. According to increase the smoothing window length, this study shows that the CV trend of peak LE was decreased. However, the CV of mean LE was analyzed constant fluctuation trend regardless of the smoothing window length. Conclusion: Based on these results, we expected that using the mean LE and 300ms window length increased reproducibility and signal noise ratio during repetitive dynamic muscle contraction. Application: These results can be used to provide fundamental information for repetitive dynamic EMG signal processing.
\end{abstract}

Keywords: Electromyography, Amplitude, Linear envelope, Coefficient of variation, Reproducibility

\section{Introduction}

표면 근전도를 이용하여, 국부 근육의 활성도, 피로도, 활 성 전위 전도 속도 등 생체역학적으로 다양한 속성과 이를 바탕으로 유용한 정보를 파악할 수 있다(DeLuca, 1997).

근골격 시스템에서는 근 수축에 따라 근섬유 막에서 운 동 단위 활성 전위가 전도되어 발화율로 표현할 수 있고, 발화율은 근전도 신호의 진폭 속성을 통해 근활성도 평가 기준이 된다. 근전도 신호의 진폭을 파악하기 위한 다양한
신호 처리 기법들로서 평균 절대값(MAV; mean absolute value), 적분(integrated $\mathrm{EMG}$ ), 제곱평균제곱근(RMS; root mean square), 포락 검출(envelope detection), 위상 평균 (ensemble averaging) 기법들이 제시되고 있다(Kumar and Mital, 1996; Soderberg, 1992).

근전도 신호는 실제 근신경계에서 발생되는 신호뿐만 아 니라 피부 온도, 전극 전도 상태, 심박동, 주변 전류 등의 원 치 않는 노이즈가 포함된다. 이러한 신호의 노이즈를 감소시 키기 위한 방법 중 하나로 신호 처리 과정에서 구간 이동 평 균 필터 기법을 사용한다. Clancy et al.(2008)은 힘이 변화

Corresponding Author: Myung-Chul Jung. Department of Industrial and Information Systems Engineering, Ajou University, Suwon, $443-749$.

Phone: 031-219-2981, E-mail: mcjung@ajou.ac.kr

Copyright@2011 by Ergonomics Society of Korea(pISSN:1229-1684 eISSN:2093-8462). All right reserved. 
하는 근 수축 동안 아래팔의 천지굴근과 요측수근신근에 대 하여 평균 절대값으로 활성도를 평가할 때 $500 \mathrm{~ms}$ 구간 이 동 평균 필터를 사용하였으며, Calder et al.(2008)의 연구에 서는 상완요골근의 최대 등척성 근 수축에 따라 $200 \mathrm{~ms}$ 구 간 이동 필터를 적용하였다. Burden and Bartlett(1999)는 상완이두근 근전도 신호의 진폭을 정규화하는 과정에서 구간 이동 창을 $100 \mathrm{~ms}$ 로 설정하였다. 이와 같이 근활성도를 파 악하는 선행 연구는 근섬유의 길이가 변하지 않는 등척성 근 수축을 고려하였고, 연구간 적용한 스무딩 구간의 차이가 있었다.

하지만, 인간의 움직임은 동적 상태이며, 특히 제조업의 생산/조립 라인이 구축된 산업 현장에서는 단순 반복 동작이 높은 비율을 차지하고 있다. 이러한 동적 상태에서는 시간 경과에 따라 근섬유 두께 및 길이가 변화하며 표면 근전도 전극과 근섬유 간의 거리 차이가 발생한다. 또한 근 수축 속 도 변화에 따라 근육-건 모멘트의 차이가 발생하며, 동적 근 수축에 따른 신속한 운동 단위 모집은 비정형적인 신호 속성을 지니게 된다(Farina et al., 2001; Gerus et al., 2010). 따라서 동적 근 수축에 따른 근전도 신호의 해석은 정적 근 수축과는 다르게 접근해야 한다.

Oliveira and Gonçalves(2009)는 상지 부위 근육의 정/ 동적 수축 형태에 따른 피로도를 분석하는 연구에서 RMS 를 적용하여 동적 근 수축 신호의 진폭을 평가하였다. 보조 장비의 착용 유무에 따른 허리부위 근육의 피로도를 분석 한 Lotz et al.(2009)의 연구에서는 5 분 간격으로 평균적 인 RMS로서 시간 경과에 따른 진폭의 추이를 파악하였다. Aagaard et al.(2002)는 등속성 근 수축의 진폭을 적분법을 사용하여 분석하였다. Larsson et al.(1999)은 무릎 굴곡 동 작에 따른 근전도 신호의 재현성을 분석하였으며, RMS로서 신호의 진폭을 파악하였다.

이와 같이 동적 근 수축에 따른 근전도 신호의 진폭을 분 석한 대부분의 선행 연구는 널리 알려진 RMS 기법으로서 근활성도를 파악하였다. 하지만 유럽의 SENIAM(Surface Electromyography for Non-Invasive Assessment of Muscle)에서 수행된 연구 결과에서는 RMS 지표로서는 등 척성 근 수축의 진폭을 분석할 것을 권고하고 있으며, 동적 근 수축의 경우 이와 다르게 포락 검출법 및 위상 평균 기법 의 사용을 제안하였다(Freriks and Hermens, 1999). 이러 한 권고사항을 준수하여 Martins et al.(2008)의 연구에서 는 실험 조건 별로 등척성과 동적 근 수축을 분류하여 각각 $\mathrm{RMS}$ 와 포락 검출법으로 근전도의 진폭을 파악하였다. 일반 인과 환자의 보행 패턴에 따른 정규화 기법의 차이를 분석한 Benoit et al.(2003)은 하지 6부위 근육의 근활성도를 포락 검출법으로 분석하였으며, 반복적인 보행 동작에 따른 근활 성도의 재현성을 비교하기 위하여 변동 계수(coefficient of variation)를 적용하였다. 이와 비슷하게 Biasotto-Gonzalez et al. (2010) 과 Fischer et al.(2010) 도 포락 검출법과 변동 계수를 사용하여 반복간 근활성도의 재현성을 파악하였다.

따라서 본 연구의 목적은 피실험자 내 반복간 근활성도 재현성의 차이를 비교하는 것이다. 이에 따라 포락 검출법을 적용하여 동적 근 수축에 따른 근전도 신호를 효과적으로 파악할 것이며, 진폭 추출 기법과 스무딩 사이즈의 차이에 따른 근활성도의 재현성 변화를 분석할 것이다.

\section{Method}

\subsection{Subject}

본 실험에 참가하는 피실험자로서 20대 남성 10명을 모 집하였다. 이들은 모두 지난 5년간 어깨 부위에 근골격계 질환 병력이 없었으며, 오른손잡이 였다. 피실험자의 기본적 인 신체 특성치의 평균(표준 편차)은 Table 1 에 제시하였다.

Table 1. Anthropometric information of subjects

\begin{tabular}{l|c|c|c|c|c}
\hline & $\begin{array}{c}\text { Age } \\
(\text { year })\end{array}$ & $\begin{array}{c}\text { Height } \\
(\mathrm{cm})\end{array}$ & $\begin{array}{c}\text { Weight } \\
(\mathrm{kg})\end{array}$ & $\begin{array}{c}\text { Elbow height } \\
(\mathrm{cm})\end{array}$ & $\begin{array}{c}\text { Arm length } \\
(\mathrm{cm})\end{array}$ \\
\hline Mean & 27.30 & 175.50 & 74.81 & $\begin{array}{c}108.05 \\
( \pm 3.62)\end{array}$ & $\begin{array}{c}61.14 \\
( \pm 2.25)\end{array}$ \\
\hline (S.D. $)$ & $( \pm 1.06)$ & $( \pm 4.49)$ & $( \pm 6.57)$ & $( \pm .6)$ \\
\hline
\end{tabular}

\subsection{Equipment}

각 근육의 높은 활성도를 얻기 위하여 $7 \mathrm{~kg}$ 덤벨을 중량 물로서 사용하였으며, 무게는 Mital et al.(1993) 문헌에서 제시하는 남성의 한손 들기의 한계중량 $(9 \mathrm{~kg})$ 과 본 연구의 작업 빈도 $(10 \mathrm{cyc} / \mathrm{m})$ 를 고려하여 선정하였다. 실험이 수행 된 입식 작업대는 높이 조절이 가능하였으며, Sanders and McCormick (1993) 문헌에서 제안하는 중작업 시의 높이 를 반영하여 피실험자의 굽힌 팔꿈치 높이 $-15 \mathrm{~cm}$ 로 설정 하였다. 반복적인 동적 근 수축의 근전도 신호는 Telemyo 2400T DTS telemetry (NORAXON, Scottsdale, Arizona, $\mathrm{USA}$ ) 장비를 사용하여 측정하였다.

\subsection{Experimental design}

본 실험은 피실험자 내 실험 설계로서 5 부위 근육(상완이 두근, 전면삼각근, 후면삼각근, 상부승모근, 하부승모근), 근 활성도 추출 기법(mean, peak), 스무딩 사이즈 $(50,100, \cdots$, $500 \mathrm{~ms}$ )를 독립변수로 선정하였다. 이에 따른 종속변수로 서 각 주기 별 LE(linear envelope)를 산출하여 변동 계수 
(coefficient of variation)로서 신호의 변동성을 분석하였다 (Equation 1). 변동 계수는 피실험자 내 또는 피실험자 간에 동일한 실험 조건에서 반복에 따른 재현성을 파악하기 위하 여 주로 사용되며, 변동 계수가 낮을수록 반복간 산포가 낮다 는 것을 의미하며 이는 재현성의 증가로 나타낸다(Hopkins, 2000).

$$
C V=(\text { S.D./mean }) \times 100 \%
$$

\subsection{Procedure}

실험을 수행하기 전, 피실험자 전원에게 실험 참가 동의를 얻었으며 전반적인 프로토콜을 숙지시켜 친숙한 환경에서 실험에 임하도록 하였다.

피실험자 피부의 전기적 저항을 최소화하기 위하여 피부 표면의 잔털을 제거하고 알코올과 솜을 이용하여 깨끗이 닦 은 후, 완벽히 증발시켰다. SENIAM에서 제안하는 전극 부착 위치에 따라 해당 근육의 피부 표면에 수성 펜을 사용하여 미리 부착 위치를 표시하였다(SENIAM recommendation). 상완 이두근, 전/후면 삼각근, 상/하부 승모근 총 5 부위의 상지 근육에서 근전도 신호를 측정하였다(Figure 1).
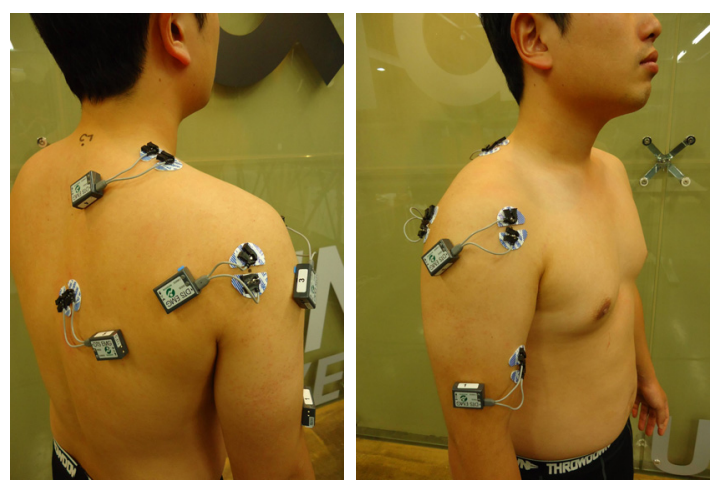

Figure 1. Position of surface electrodes

표면 전극 센서는 $\mathrm{Ag} / \mathrm{AgCl}$ 양극성 전극으로 구성되며 각 전극의 지름은 $10 \mathrm{~mm}$, 전극 중심 사이의 거리는 $20 \mathrm{~mm}$ 였다. 모든 근전도 신호의 대역폭은 10 500Hz, 16bit의 $\mathrm{ADC}$ (analog digital converter)를 사용하였으며, CMRR (common mode rejection ratio) $>100 \mathrm{~dB}$, Noise $<1 \mu \mathrm{V}$, Gain*1000, Sampling rate $1,500 \mathrm{~Hz}$ 로 설정하였다.

Figure 2와 같이 피실험자는 입식 작업대 위 몸의 중심에 위치한 덤벨을 $60 \mathrm{~cm}$ 거리의 종점까지 일정한 빈도로 우측 수평 이동시키는 동작을 10 회 반복 수행하였다. 수평 거리는 대한민국 20 대 남성의 평균 팔 길이를 고려하였으며(Size-
Korea, 2004), 작업 빈도는 MyoResearch XP Master Edition 1.07.25(NORAXON, Scottsdale, Arizona, USA) 소프트웨어에서 제공하는 메트로놈 기능으로 $10 \mathrm{cyc} / \mathrm{m}$ 로 고 정하였다. 피실험자가 종점으로 이동시킨 중량물은 보조 연 구원에 의해 시점으로 재정렬 되었다.

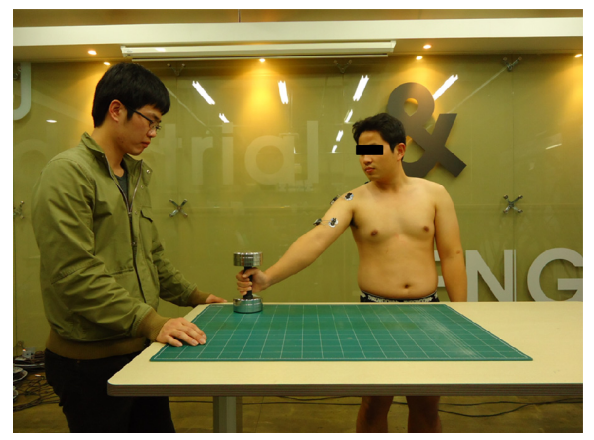

Figure 2. One-handed right horizontal lifting task

\subsection{Signal processing and statistics}

모든 근전도 신호는 MyoResearch XP Master Edition 1.07.25(NORAXON, Scottsdale, Arizona, USA) 소프트웨 어에서 제공하는 ECG reduction function으로 심박동 신호 를 제거한 후, 총 10 주기의 신호에서 초기와 말단의 3 주기 를 제외하고 4 7번째 신호를 추출하였다. 추출된 근전도 신

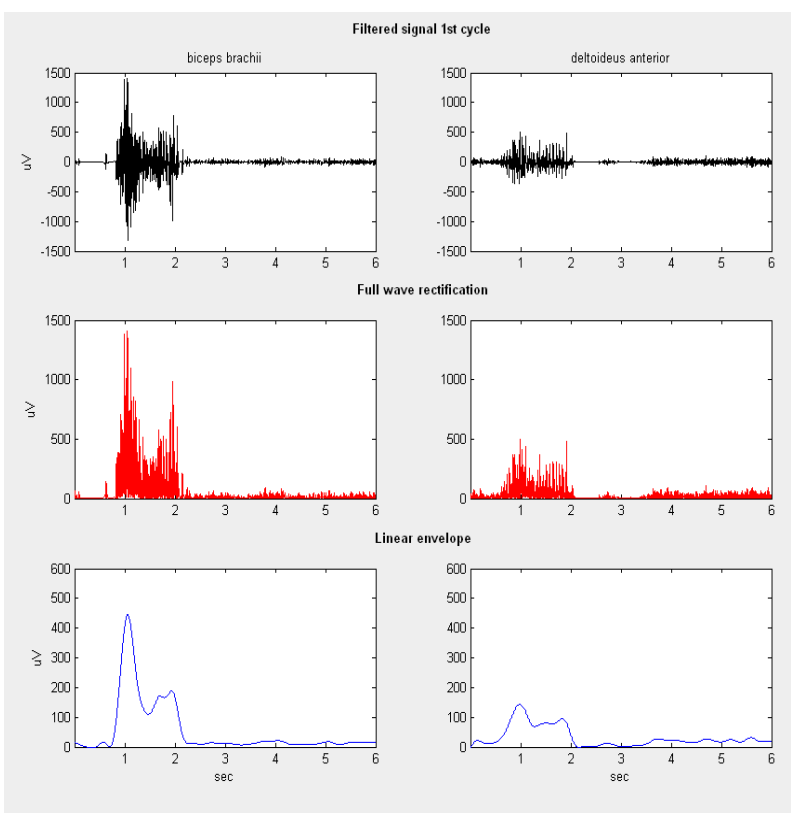

Figure 3. Example of signal processing (Describe to biceps brachii and anterior deltoid) 
호는 full wave rectification 후, Dual-pass Butterworth lowpass filter (cutoff $5 \mathrm{~Hz}$ ) 로서 LE를 산출하였다(Winter, 2005). 산출된 LE 데이터로서 스무딩 사이즈에 따른 구간 이동 평균 필터를 적용하여, mean/peak value로서 총 4주기 에 의한 변동 계수를 산출하였다. 모든 근전도 데이터 처리 에는 offline MATLAB 7.0.4 (Mathworks, Natick, MA, US) 을 사용하였다(Figure 3).

각 독립변수에 따른 기술적 통계치인 평균과 표준편차를 구하고 변동 계수에 따른 분산분석 $(\alpha=0.05)$ 을 실시하여, 주효과 및 교호작용을 분석하였다. 또한 유의하게 분석된 인자에 대해서 사후검증으로서 Tukey 다중비교(Tukey multiple comparison test) 분석을 실시하여 수준 별 유의한 차이를 파악하였다.

\section{Results}

변동 계수에 따른 각 독립변수의 분산분석 결과, 주 효과 로서 근활성도 추출 기법 $(F=15.48 p=.0034)$ 과 스무딩 사 이즈 $(F=7.21 p<.0001)$ 는 통계적으로 유의한 차이가 있는 것으로 분석되었으며, 각 근육 간에는 유의한 차이가 없었다. Figure 4와 같이 평균적으로 Mean LE가 Peak LE보다 변 동 계수가 약 $3.2 \%$ 가량 낮게 나타났으며, 스무딩 사이즈 증가에 따라 변동 계수는 약간 감소하는 추이로 파악되었다. 비록 스무딩 사이즈에 따라 변동 계수는 통계적으로 유의하 게 분석되었지만, $50 \mathrm{~ms}$ 에서 $500 \mathrm{~ms}$ 까지 변동 계수의 변화 량은 약 $0.8 \%$ 가량 감소하였다. 이에 따른 다중비교 결과, 50 300ms, 100 350ms, 150 400ms, 200 500ms 수 준 별로 유의한 차이가 있는 것으로 분석되었다(Figure 5).

2,3 차 교호작용 중 추출 기법*스무딩 사이즈 간의 교호 작 용 $(F=6.96 p<.0001)$ 만 유의한 차이로 분석되었다(Figure

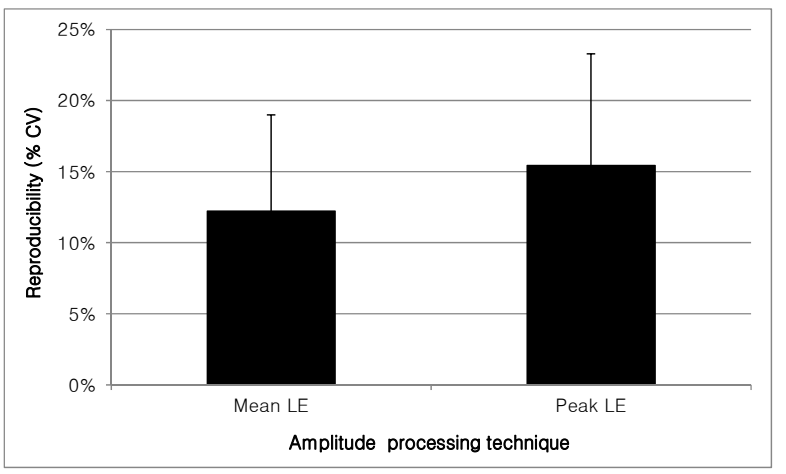

Figure 4. Significant result of main effect by the amplitude processing techniques
6). 전반적으로 Peak LE의 변동 계수가 Mean LE보다 높게 분석되었으며, 스무딩 사이즈 증가에 따라 Peak LE의 변동 계수는 감소하는 추이로 나타났으며, Mean LE는 스무딩 사 이즈의 증가와 무관하게 약 $12.2 \%$ 의 일정한 변동 계수로 파악되었다.

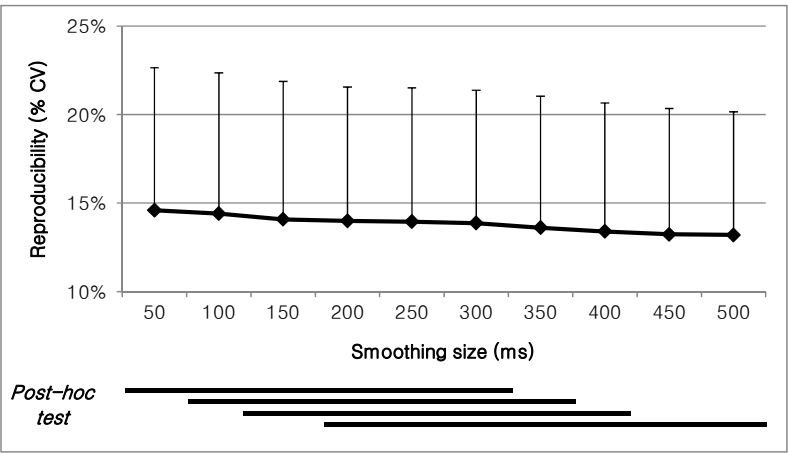

Figure 5. Significant result of main effect by the smoothing size and Tukey multiple comparison test

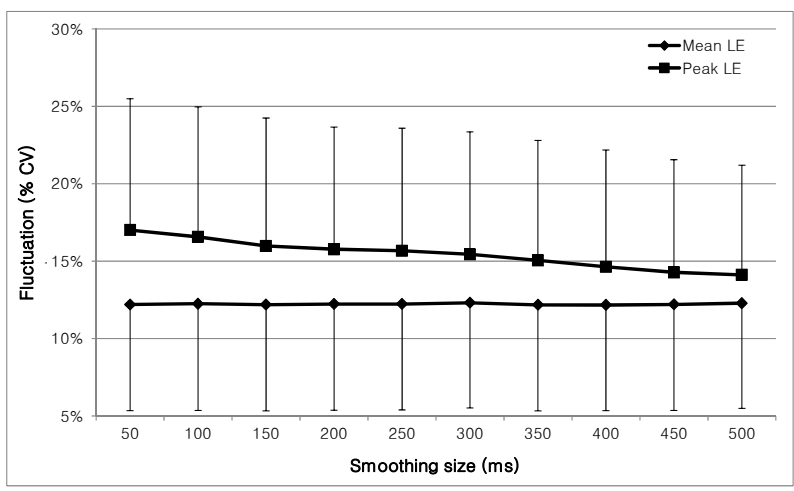

Figure 6. Significant result of two-way interaction effect by amplitude processing technique*smoothing size

\section{Discussion}

본 연구는 SENIAM recommendation을 준수하여 동적 근 수축에 따른 근전도 신호의 진폭을 포락 검출법으로서 효 과적으로 파악하였으며, 변동 계수 값을 이용하여 진폭 추출 기법과 스무딩 사이즈의 변화에 따른 재현성을 비교 분석하 였다.

Peak LE보다 Mean LE의 변동은 낮게 분석되었으며, 반 복적인 동작에서 근전도 신호의 평균값으로 활성도를 추출 하는 것이 최대값보다 상대적으로 재현성이 증가되었다는 
것을 의미한다. 이러한 효과는 동적 근 수축에 따른 비정형 적인 근전도 신호에 의해 민감한 최대값의 변동성이 높아진 것으로 판단된다. Hibbs et al.(2011) 연구도 코어 운동 시 평균값의 변동성이 최대값보다 낮게 분석되었으며, 이는 신 체의 무게 중심 변화에 따라 균형을 유지하기 위해 단기의 강한 근활성도 발생 효과로 최대값의 높은 변동성을 설명하 였다. 본 연구도 $7 \mathrm{~kg}$ 의 중량물을 몸의 중심으로부터 외부로 우측 수평 이동시키는 동작에서 무게 중심의 변화로 인하여 동일한 효과가 발생하여 평균적인 Peak LE의 변동 계수가 높았다(Figure 6). 이와 같이 더욱 높은 에너지를 요하는 동 작(예: 태권도, 사이클링)일수록 동적 상태 및 동작 범위가 증가하여 에너지 소비량 및 근전도 등 생리적 속성의 변동성 은 증가하게 된다(Aggeloussis et al., 2007; Pfeiffer et al., 2006). 반면 등척성 근 수축을 고려한 Fischer et al.(2010) 의 연구에서는 근활성도 정규화에서 주로 사용되는 $\mathrm{MVC}$ (Maximum Voluntary Contraction) 및 MVE(Maximum Voluntary Exertion) 기준 값의 데이터 처리에서는 오히려 민감한 최대값이 변동성을 낮추어 높은 재현성을 보장한다 고 보고하였다. 따라서 본 연구 결과를 토대로 추후 반복적 인 동작간 높은 근활성도 재현성을 위하여 Mean LE 사용을 권고할 수 있을 것이다.

스무딩 사이즈의 증가는 Mean LE 변동성에 영향을 미치 지 않았으며, Peak LE의 변동성을 감소시켰다. 앞서 보고하 였듯이 근전도 신호의 비정형적인 속성으로 인해 민감한 최 대값이 스무딩 사이즈의 영향을 높게 받은 것으로 여겨진다. 이론적으로 스무딩 사이즈의 증가는 신호를 매끄럽게 변조 하여 노이즈 제거 효과 및 변동 오차(variance error)를 감 소시킬 수 있다. 하지만 스무딩 사이즈가 증가하는 만큼 편 향 오차(bias error)가 증가하며 원신호가 내포하는 정보를 상실하게 된다. 실제로 아직까지 표면 근전도 신호에서 적절 한 스무딩 사이즈의 표준은 제시되어 있지 않으며, 근전도 신호의 진폭 변화량이 높은 동적 상황에서는 가급적 작은 스무딩 사이즈를 권장하고 있다(Clancy, 1999; SENIAM recommendation). 반면 St-Amant et al.(1998)의 연구에 서는 동적 근 수축에 따른 구간 이동 평균 필터의 스무딩 사 이즈가 증가할수록 신호 대 잡음비 (signal to noise ratio)가 일정하게 증가하는 것으로 분석되었다. 따라서 동적 근 수축 고려 시, 스무딩 사이즈가 너무 작아도 근전도 신호의 신호 대 잡음비가 감소하여 노이즈가 증가될 수 있다는 것을 의미 한다. 비록 Fischer et al.(2010)은 정적 근 수축을 고려하 였지만, $500 \mathrm{~ms}$ 의 구간 이동 평균 필터를 적용한 최대값은 실제 최대값 및 평균값과 비교하여 피실험자 내 가장 높은 재현성을 보여주었다. Figure 5에서 스무딩 사이즈에 따른 사후 검증 결과 50 300ms 수준까지는 통계적으로 유의한 차이가 없는 것으로 분석되었다. 이에 따라 동적 근 수축에
따른 근전도 신호 해석 시, 약 $300 \mathrm{~ms}$ 의 스무딩 사이즈까지 허용하여 구간 이동 평균 필터의 적용은 작은 스무딩 사이즈 보다는 신호 대 잡음 비의 증가와 동시에 변동성 감소 효과 를 나타낼 수 있을 것으로 예상한다.

흥미롭게 본 연구의 분석 결과 전반적으로 변동 계수의 평 균에 따른 표준편차가 다소 높게 나타났다. 일반적으로 표면 근전도 데이터는 실험 조건의 통제가 우수할지라도 동일한 조건에서 근전도 신호의 반복 측정은 신호가 일정하게 재현 되기 어렵다. 이는 운동 단위 소집과 관련된 신경 패턴의 차 이로 인해 누화(cross-talk) 및 준 임의적(quasi-random) 특성이 매회 근전도 신호에 영향을 미치며 부가적으로 피부 고유 저항, 발열, 혈류량 등의 다양한 요인이 복합적으로 영 향을 미쳐 측정간 변동성이 높게 나타나게 된다(DeLuca, 1997; Farina et al., 2004). 본 연구도 이러한 영향으로 인 해 변동 계수의 표준 편차가 높게 도출된 것으로 사료된다.

추후 상지 외 다양한 근육의 근전도 신호와 추가적인 근활 성도 추출 기법(peak to peak, initial and last peak) 등을 고 려해야 할 것이며, 재현성을 비교하는 기법으로서 변동 계수 뿐만 아니라 ICC (Intra-Class Correlation) 알고리즘도 추 가 적용하여 근전도 신호의 노이즈는 감소시키고 재현성을 증가시킬 수 있는 최적의 기법을 권고하는 연구를 진행해야 할 것이다.

\section{References}

Aagaard, P. and Mayer, F., Increased rate of force development and neural drive of human skeletal muscle following resistance training, Journal of Applied Physiology, 93(4), 1318-1326, 2002.

Aggelousis, N., Gourgoulis, V., Sertsou, M., Giannakou, E. and Mavromatis, G., Repeatability of electromyographic waveforms during the Naeryo Chagi in takwondo, Journal of Sports Science and Medicine, 6(2), 6-9, 2007.

Benoit, D. L., Lamontagne, M., Cerulli, G. and Liti, A., The clinical significance of electromyography normalisation techniques in subjects with anterior cruciate ligament injury during treadmill walking, Gait and Posture, 18(2), 59-63, 2003.

Biasotto-Gonzalez, D. Ap., Berzin, F., Da Costa, J. M. and De Oliveira Gonzalez, T., Electromyographic study of stomatognathic system muscles during chewing of different materials, Electromyography and Clinical Neurophysiology, 50(2), 121-127, 2010.

Burden, A. and Barlett, R., Normalisation of EMG amplitude: an evaluation and comparison of old and new method, Medical Engineering \& Physics, 21(4), 247-257, 1999.

Calder, K. M., Stashuk, D. W. and McLean, L., Physiological characteristics of motor units in the brachioradialis muscle across fatiguing low-level isometric contractions, Journal of Electromyography and Kinesiology, 
18(1), 2-15, 2008.

Clancy, E. A., Electromyogram amplitude estimation with adaptive smoothing window length, IEEE Transactions on Biomedical Engineering, 46(6), 717-729, 1999.

Clancy, E. A., Bertolina, M. V., Merletti, R. and Farina, D., Time- and frequency-domain monitoring of the myoelectric signal during a long-duration, cyclic, force-varying, fatiguing hand-grip task, Journal of Electromyography and Kinesiology, 18(5), 789-797, 2008.

DeLuca, C. J., The use of surface electromyography in biomechanics, Journal of Applied Biomechanics, 13(2), 135-163, 1997.

Farina, D., Merletti, R. and Enoka, R., The extraction of neural strategies from the surface EMG, Journal of Applied Physiology, 96(4), 1486 $-1495,2004$.

Farina, D., Merletti, R., Marisa, N. and Caruso, I., Effect of joint angle on EMG variables in leg and thigh muscles, IEEE Engineering in Medicine and Biology, 20(6), 62-71, 2001.

Fischer, S. L., Belbeck, A. L. and Dickerson, C. R., The influence of providing feedback on force production and within-participant reproducibility during maximal voluntary exertions for the anterior deltoid, middle deltoid, and infraspinatus, Journal of Electromyography and Kinesiology, 20(1), 68-75, 2010.

Freriks, B. and Hermens, H. J., SENIAM 9: European Recommendations for Surface Electromyography. ISBN: 90-75452-14-4, Enschede, The Netherlands: Ressingh Research and Development, 1999.

Gerus, P., Rao, G., Buchanan, T. S. and Berton, E., A clinically applicable model to estimate the opposing muscle groups contributions to isometric and dynamic tasks. Annals of Biomedical Engineering, 38(7), 2406-2417, 2010

Hibbs, A. E., Thompson, K. G., French, D. N., Hodgson, D. and Spears, I. R., Peak and average rectified EMG measures: which method of data reduction should be used for assessing core training exercise. Journal of Electromyography and Kinesiology, 21(1), 102-111, 2011.

Hopkins, W. G., Measures of reliability in sports medicine and science. Sports Medicine, 30(1), 1-15, 2000.

Korean Agency for Technology and Standards, Size Korea, 5th Korean human anthropometric research project report, 2004.

Kumar, S. and Mital, A., Electromyography in ergonomics, Taylor \& Francis, 1996.

Larsson, B., Månsson, B., Karlberg, C., Syverstsson, P., Elert, J. and Gerdle, B., Reproducibility of surface EMG variables and peak torque during three sets of ten dynamic contractions, Journal of Electromyography and Kinesiology, 9(5), 351-357, 1999.

Lotz, C. A., Agnew, M. J., Godwin, A. A. and Stevenson, J. M., The effect of an on-body personal lift assist device(PLAD) on fatigue during a repetitive lifting task. Journal of Electromyography and Kinesiology, 19(2), 331-340, 2009

Martins, J., Tucci, H. T., Andrade, R., Araújo, R. C., Bevilaqua-Grossi, D. and Oliveira, A. S., Electromyographic amplitude ratio of serratus anterior and upper trapezius muscles during modified push-ups and bench press exercises. Journal of Strength and Conditioning Research, 22(2), 477-484, 2008

Mital, A., Nicholson, A. S. and Ayoub, M. M., A guide to manual material handling, Taylor \& Francis, 1993.
Oliveira, A. S. and Gonçalves, M., EMG amplitude and frequency parameters of muscular activity: Effect of resistance training based on electromyographic fatigue threshold, Journal of Electromyography and Kinesiology, 19(2), 295-303, 2009.

Pfeiffer, K. A., Schmitz, K. H., McMurray, R. G., Treuth, M. S., Murray, D. M. and Pate, R. R., Physical activities in adolescent girls: variability in energy expenditure, American Journal of Preventive Medicine, 31(4), 328-331, 2006

Sanders, M. S. and McCormick, E. J., Human factors in engineering and design, 7th ed., McGrow-Hill, Inc, 1993.

Soderberg, G., Selected Topics in Surface Electromyography for Use in the Occupational setting: Expert Perspectives, DHHS(NIOSH) Publication, 1992.

St-Amant, Y., Rancourt, D. and Clancy, E. A., Influence of smoothing window length on electromyogram amplitude estimates, IEEE Transactions on Biomedical Engineering, 45(6), 795-799, 1998.

Winter, D. A., Biomechanics and motor control of human movement, $3 r d$ ed., Newjersey: John Wiley and Sons, 2005.

\section{Author listings}

Seung-Min Mo: msmergo@ajou.ac.kr

Highest degree: M.S., Department of Industrial and Information Systems Engineering, Ajou University

Position title: Ph.D. Candidate, Department of Industrial and Information Systems Engineering, Ajou University

Areas of interest: Ergonomics, Manual Material Handling, and Electromyography

\section{Jong-Seon Kwag: jskwag@enterpriz.net}

Highest degree: M.S., Department of Industrial Engineering, Hanyang University

Position title: Ph.D. Candidate, Department of Industrial and Information Systems Engineering, Ajou University

Areas of interest: Work Design, Ergonomics, and Signal Processing

Myung-Chul Jung: mcjung@ajou.ac.kr

Highest degree: Ph.D., Department of Industrial Engineering, Pennsylvania State University

Position title: Associate Professor, Department of Industrial and Information Systems Engineering, Ajou University

Areas of interest: Work Design, Ergonomics, and Product Development

Date Received : 2010-12-01

Date Revised :2011-10-26

Date Accepted : 2011-10-28 